\title{
A rare variation in facial artery and its implications in facial surgery: Case report
}

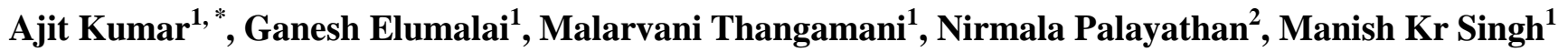 \\ ${ }^{1}$ Department of Anatomy, Tribhuvan University, National Medical College, Birgunj, Nepal \\ ${ }^{2}$ Department of Anatomy, Kathmandu University, Nobel Medical College \& Teaching Hospital, Biratnagar, Nepal
}

\section{Email address:}

physiovesalius@gmail.com (G. Elumalai), ajit.anatomy@gmail.com (A. Kumar), malardewdrop@gmail.com (M. Thangamani), mailtonirmala.p@gmail.com (N. Palayathan), manishkrsingh@gmail.com (M. K. Singh)

\section{To cite this article:}

Ajit Kumar, Ganesh Elumalai, Malarvani Thangamani, Nirmala Palayathan, Manish Kr Singh. A Rare Variation in Facial Artery and Its Implications in Facial Surgery: Case Report. Journal of Surgery. Vol. 2, No. 5, 2014, pp. 68-71. doi: 10.11648/j.js.20140205.13

\begin{abstract}
Facial artery is usually the main artery supplying the face. It gives three named branches on the face, the inferior labial, the superior labial and the lateral nasal and continues as the angular artery. Face is also supplied by the transverse facial artery and the arteries accompanying the cutaneous nerves. In our present case report, we observed that the lingual and facial arteries were originating from the front of External Carotid artery (ECA) as a common linguofacial trunk on the left side and coursed upwards towards the mandible for about $1.2 \mathrm{~cm}$ and then divided into facial and lingual arteries. We observed that the facial artery terminated as Inferior labial artery as end artery (without anastomoses). The other branches for the face namely Superior labial, lateral nasal and angular arteries are arises from the Transverse facial artery. Conclusion: In this study, we noticed that a variation in the morphological aspect of arterial pattern of face, until then not documented. In this sense, the objective of this study was to report a variation of the facial artery and to analyze it relative to the literature state of the art. The present case may provide useful information in different fields of oral and maxillofacial surgery.
\end{abstract}

Keywords: Facial Artery, Transverse Facial Artery, Flap Procedure, Maxillofacial Surgery

\section{Introduction}

Vascular variations are congenital morphological differences that arise in the human body. Although, for the most part, do not cause injury to the individual, may be important in cases where it is necessary a specific access to the vascular system. It is very important for surgeons to know the exact frequency and variations of the arteries in the areas where they have to operate on (Didio, 1999). The anatomic understanding of the facial artery and its branches are especially important in the practice of medical and dental care, in the surgeries of neck and face; and also for the radiologist to understand and interpret facial artery imaging when undertaking head angiography. Moreover, anatomical information on the head and neck arteries are important for less invasive treatment of diseases in those regions. In general, knowledge of angio-architecture contributes to skilful segmentectomies, helping to preserve tissue, perform better surgery, and reduce both anesthesia and hemorrhage (Hollinshead, 1982; Kruger, 1984).

In the mending of lip defects, using the techniques such as the Abbe flap procedure, knowledge of the vascular anatomy of the face is indispensible. This type of reconstructive lip flap is used in the rebuilding of the lateral upper and lower lip defects due to cancerous, congenital or traumatic injuries. This involve one-third of the upper $r$ lower lip, in case where the oral commissure intact. Utilization of the Abbe flap involves rotation of the flap on its vascular pedicle consisting a large part of the Superior labial artery. The Estlander and Goldstein flap (involving one-half to two-thirds of the lip) procedures also involve similar consideration of the labial vasculature.

The facial artery normally arises from the external carotid artery, just above the lingual artery, at the level of greater cornu of hyoid bone in the carotid triangle. It then passes upwards and forwards medial to the ramus of the mandible. It passes deep to the superficial part of the submandibular salivary gland making a characteristic loop, winds around the base of the mandible to enter the face at anteroinferior angle of the masseter muscle. In the face, it 
runs upwards and forward, laterals to angle of the mouth, and ends as angular artery at medial angle of eye. Its branches in the face include: inferior labial artery, to the lower lip; superior labial artery, to the upper lip; lateral nasal artery, to supply the ala and dorsum of the nose (Standring, 2008).

The reported variations of the facial artery include: its intra parotid origin (Nayak, 2006); arising as a common trunk with the lingual artery as linguofacial trunk (Midy, Mauruc, Vergnes et al., 1986); its function being taken over by maxillary artery, transverse facial artery or the nasal branch of ophthalmic artery when absent (Bergman et al., 1988); its termination as submental artery, labial artery or lateral nasal artery (Bergman et al., 1988); and, a case of duplex artery (Koh et al., 2003).

However, in the case studied, we noticed a variation in the morphological aspect of arterial pattern of face, until then not documented. In this sense, the objective of this study was to report a variation of the facial artery and to analyze it relative to the literature state of the art. The present case may provide useful information in different fields of oral and maxillofacial surgery.

\section{Material and Methods}

The study involved the head and neck dissection of a 65year-old male cadaver of Nepal origin in the Department of Anatomy, National Medical College, Birgunj, Nepal. The dissection of head and neck was carried out according to the instructions by Cunningham's Manual of Practical Anatomy, Volume-3. The dissections took place during the year 2013-2014. The body was preserved by the injection of a formalin-based preservative ( $10 \%$ formalin) and stored at $-40 \mathrm{C}$.

\section{Case Report}

On the left side of face, the lingual and facial arteries were arises from the anterior part of External Carotid artery (ECA) as a common linguofacial trunk and coursed upwards towards the mandible for about $1.2 \mathrm{~cm}$ and then divided into facial and lingual arteries. We observed that the facial artery terminated as Inferior labial artery as end artery (without anastomoses). The other branches for the face like Superior labial, lateral nasal and angular arteries are arises from the Transverse facial artery (Fig: 2 and 3). Also we noticed that, the ascending pharyngeal artery is originated from the occipital artery, but it is usually arises from the External carotid artery as medial branch (Fig:1).

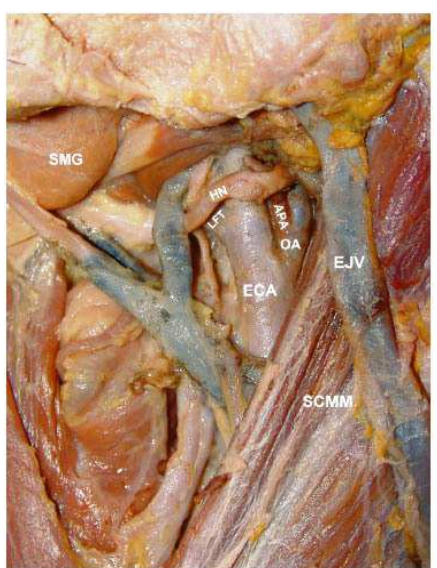

Figure 1. In the left side of the neck, the linguofacial trunk (LFT) arises from anterior surface of the external carotid artery (ECA) and the ascending pharyngeal artery (APA) originated from the occipital artery (OA). SMG; Submandibular gland, SCMM; Sternocleidomastoid muscle, EJV; External jugular vein, HN; Hypoglossal nerve.

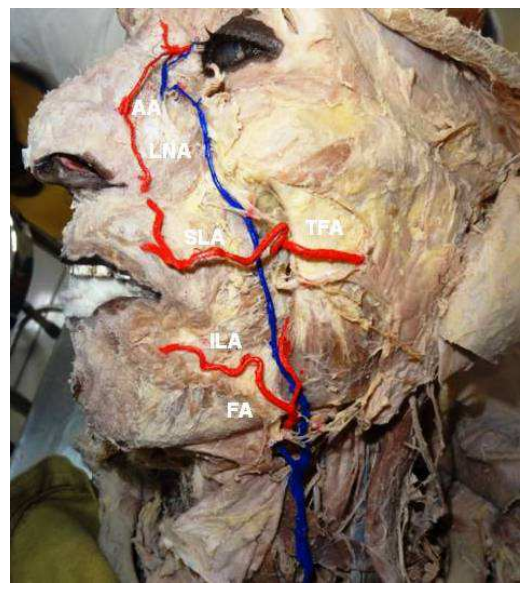

Figure 2.

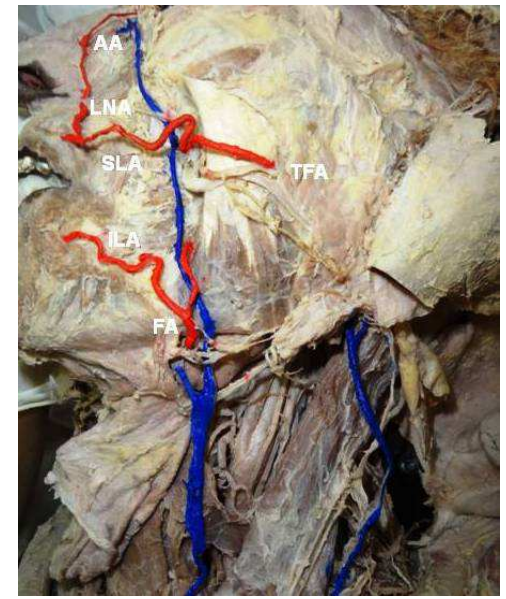

Figure 3.

Figure 2 and 3. In the left side of the face, the facial artery (FA) arise out from the common Linguofacial trunk, enters face and terminate as end artery after gives the Inferior labial branch (ILA). The other branches of face like Superior labial artery (SLA), Lateral Nasal artery (LNA) and angular artery (AA), are arises from the Transverse facial artery (TFA). 


\section{Discussion}

The Common Carotid Artery (CCA) and its branches provide the major source of blood to the region of head and neck. The CCA bifurcates at the level of upper border of thyroid cartilage (Williams et al.,1995; Skandalakis et al.,1994).Variations in the branching pattern of carotid system is not uncommon. A study has done by Zumre et al.(2005) on human fetuses found a thyro-lingual trunk in $2.5 \%$, a thyrolinguo-facial trunk in $2.5 \%$ and linguofacial trunk in $20 \%$ (Zumre et al.,2005). According to a study did by Bergman et al. facial artery may replace lingual artery and supply the sublingual gland. Similarly origin of linguo-facial trunk bilaterally also reported (Kishve et al.,2011). But in the present study, linguo-facial trunk was found unilaterally and was on found the left side. Unusual case of origin of the superior thyroid and lingual arteries was described by Thomson, in his notes on unusual variations (Thomson, 1885). A right sided ECA branched into superior thyroid, lingual and occipital arteries directly at its origin as observed (Gluncic et al.,2001).

In the present study superior thyroid artery originated from the front of ECA below the tip of greater cornua of hyoid bone. The occipital artery arose from the posterior aspect of ECA opposite the origin of linguofacial trunk. Mahendrakar reported unilateral agenesis of lingual artery (Mahendrakar,2007). Some author reported that ascending pharyngeal and occipital arteries arose from internal carotid artery and no specific ECA was found in some cases (Kaneko et al.,1996). Superior thyroid artery and lingual arteries were arising from a common trunk about $30 \mathrm{~mm}$ beneath the carotid bifurcation on right side as noted (Lemaire et al.,2001). Variation in branching pattern of ECA on both the sides are rare findings which impart useful knowledge for the surgeons while operating on the face and neck regions (Kishve et al.,2011).

The anomalous branching pattern of common linguofacial trunk may have implications in the surgical field and it may tend to have a more medial course or a more medial origin. This brings the facial and lingual arteries in close proximity to the tonsillar fossa, thereby increasing the risk of iatrogenic injury (Fred,2013). According to Toshinori et al. (2013), prior to super selective intra-arterial catheterization or microsurgical reconstruction for head and neck cancer, it is important to recognize an anatomic variation like linguofacial trunk (Toshinori et al.,2013)

\section{Conclusion}

Our anatomical variation report, as well as many anatomical variations described in the literature, can affect the surgeon's ability to use certain local flaps and, with the advent of facial transplantation, may become important for the development of subunit transplantation. Although there is significant disagreement among the findings in the published cadaveric studies concerning the distribution and the frequency of variations in facial artery anatomy, there is broad agreement that anatomical variation is the rule rather than the exception. These studies have also demonstrated the need for a non-invasive in vivo technique of evaluating facial artery anatomy to ease preoperative planning in complex facial reconstructions. In our present case report, we noticed that a variation in the morphological aspect of arterial pattern of face, until then not documented. In this sense, the objective of this study was to report a variation of the facial artery and to analyze it relative to the literature state of the art. The present case may provide useful information in different fields of oral and maxillofacial surgery.

\section{References}

[1] Didio, LJ. The importance of anatomy. Annals of Anatomy, 1999,181(5): 455-465.

[2] Hollinshead, WH. Anatomy for Surgeons: Head and Neck. JB Lippincott, 1982

[3] Kruger, GO. Cirurgia Bucal e Maxilo-Facial. 5th ed. Rio de Janeiro: Guanabara Koogan, 1984.

[4] Standring, Gray's Anatomy: The Anatomical Basis of Clinical Practice. 40th ed. Philadelphia: Churchill Livingstone, 2008.

[5] Nayak, S. Abnormal intra-parotid origin of the facial artery. Saudi Medical Journal, 2006, 27(10):1602.

[6] Midy, D., Mauruc, B., Vergnes, P. and Caliot, P. A contribution to the study of the facial artery, its branches and anastomoses; application to the anatomic vascular bases of facial flaps. Surgical and Radiologic Anatomy, 1986, 8(2): 99-107.

[7] Bergman, RA., Thompson, S., Afifi, A. and Saadeh, F. Compendium of human anatomic variation. Munich: Urban \& Schwarzenberg Baltimore, 1988.

[8] Koh, KS., Kim, HJ., Oh, CS. and Chung, IH. Branching patterns and symmetry of the course of the facial artery in Koreans. International Journal of Oral \& Maxillofacial Surgery, 2003, 32(4): 414-418.

[9] Williams PL, Bannister LH, Berry MM (1995). Gray's Anatomy. In: Arteries of limbs and cardiovascular system. 38th ed. London: Churchill Livingston:1516-17.

[10] Skandalakis JE, Colborn GL, Weidman TA, Foster RS, Kingsnorth AN, Lee S S (2004) Surgical Anatomy; The Embryologic and Anatomic Basis Of Modern Surgery. Athens: PM Publications: 31-36.

[11] Zumre O, Salbacak A, Cicekcibasi AE, Tuncer I, Seker M. Investigation of the bifurcation level of the common carotid artery and variations of the branches of the external carotid artery in human fetuses. Ann. Anat. 2005,187: 361-69.

[12] Kishve PS, Kishve SP, Joshi M, Aarif SM, Kalakoti P. An unusual branching pattern of common and external carotid artery in a human cadaver. Australian Medical Journal.2011, 4(4): $180-182$.

[13] Thomson A (1885) Notes on some unusual variations in human anatomy. Anat. Physiol. 19: 328-32. 
[14] Gluncic V, Petanjek Z, Marusic A, Gluncic I. High bifurcation of common carotid artery, anomalous origin of ascending pharyngeal artery and anomalous branching pattern of external carotid artery, Surg. Radiol. Anat. 2011, 23(2):123125 .

[15] Mahendrakar MA. Variations in the branching pattern of external carotid artery - a case report. J. Anat. Soc. India. 2007, 56: $47-51$.

[16] Kaneko K, Akita M, Murata E, Imani M, Sowa K. Unilateral anomalous left common carotid artery - a case report. Ann. Anat. 1996, 178: 477-480.

[17] Lemaire V, Jacquemin G, Medot M, Fissette J. Thyrolingual trunk arising from common carotid artery: a case report. Surg Radiol Anat. 2001, 23: 135-137.
[18] Kishve PS, Kishve SP, Joshi M, Aarif SM, Kalakoti P. An unusual branching pattern of common and external carotid artery in a human cadaver. Australian Medical Journal. 2011, 4(4): $180-182$.

[19] Fred MB. Post-tonsillectomy lingual artery pseudoaneurysm. www.triomeetingposters.org/wpcontent/uploads/2012/ 12/001.pdf (accessed on 21th july 2013)

[20] Toshinori I. et al. Thyrolinguofacial trunk arising from the carotid bifurcation determined by three dimensional computed tomography angiography. Surgical and radiologic anatomy. 2013, 35(1): 75-78. 